\title{
Photonic Component Qualification and Implementation Activities at NASA Goddard Space Flight Center
}

\author{
Melanie N. Ott ${ }^{\mathrm{a}}$, Xiaodan Linda Jin ${ }^{\mathrm{b}}$, Richard F. Chuska ${ }^{\mathrm{c}}$, \\ Frank V. LaRocca ${ }^{c}$, Shawn L. Macmurphy ${ }^{c}$, Adam J. Matuszeski ${ }^{a}$, \\ Ronald S. Zellar ${ }^{\text {, }}$, Patricia R. Friedberg ${ }^{a}$, Mary C. Malenab ${ }^{b}$, \\ ${ }^{a}$ NASA Goddard Space Flight Center, Greenbelt Maryland 20771 \\ ${ }^{b}$ QSS Group Inc. 4500 Forbes Boulevard, Lanham Maryland 20706 \\ ${ }^{\mathrm{c}}$ MEI, 7404 Executive Place, Seabrook, Maryland, 20706
}

\begin{abstract}
The photonics group in Code 562 at NASA Goddard Space Flight Center supports a variety of space flight programs at NASA including the: International Space Station (ISS), Shuttle Return to Flight Mission, Lunar Reconnaissance Orbiter (LRO), Express Logistics Carrier, and the NASA Electronic Parts and Packaging Program (NEPP). Through research, development, and testing of the photonic systems to support these missions much information has been gathered on practical implementations for space environments. Presented here are the highlights and lessons learned as a result of striving to satisfy the project requirements for high performance and reliable commercial optical fiber components for space flight systems. The approach of how to qualify optical fiber components for harsh environmental conditions, the physics of failure and development lessons learned will be discussed.
\end{abstract}

Keywords: Fiber, optic, array, bundle, thermal, radiation, failure, physics, LRO, spaceflight, photonic.

\section{INTRODUCTION}

Space flight engineers that utilize photonics parts for meeting the requirements of their missions are finding that shorter term projects and leaner budgets are making the traditional parts engineering approach completely infeasible with respect to these components. Most available components are produced for the industrial and commercial markets. From a vendor's perspective, the space flight engineer has the most difficult requirements of any customer, coupled with a small budget and not enough of a volume to motivate the vendor to make major process changes. If each flight program could commit to making a large volume procurement, than product development changes to meet difficult performance requirements in a harsh environment would not seem like a waste of resources. Since it is the case that NASA programs request small amounts of very specialized components most of the components that get used are usually meant for another customer with very few changes made as possible to still comply with the NASA requirements. The best solution of course is to find a component that is being made for another government agency and in some cases that works and other times it does not. The emphasis on failure modes knowledge and tailoring test plans to the part itself and its requirements for a specific mission is necessary. Using a standard set up for military electronic parts is going to drive costs and schedule of producing such photonic components out of the range of feasibility. For commercial components used in a space flight environment, the only way to ensure reliability without over-testing is to have a thorough knowledge of packaging and parts, physics of failure. The NASA Electronic Parts and Packaging Program takes this approach when developing and qualifying commercial components for space flight requirements. In general the approach outlined in Figure 1 describes a flow chart of steps taken to qualify commercial components. 


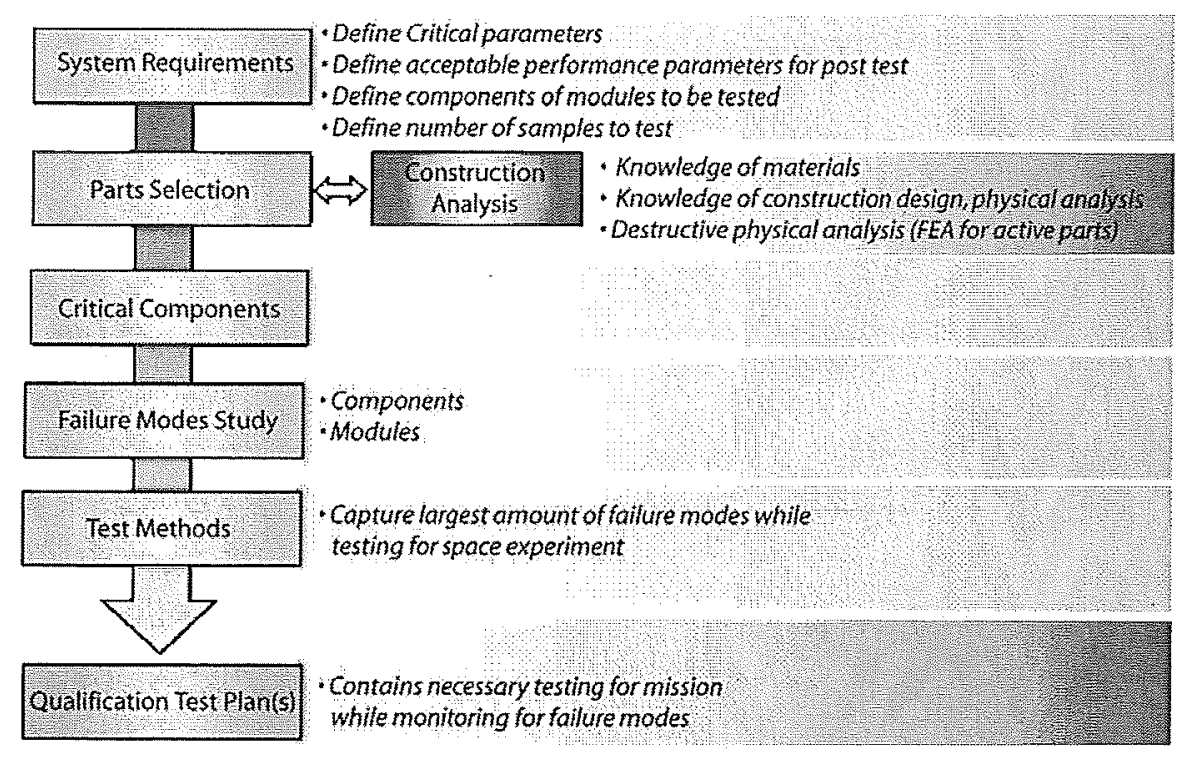

Figure 1: Steps to a Qualification Test Plan; NEPP Technology Assurance Approach [1]

In 2005 Suzzanne Falvey of Northrup Grumman drafted this flowchart after reviewing the approach outlined in a presentation given by M.Ott during the Advanced Microelectronics and Photonics for Satellites Conference.[1] This is a graphical representation of the approach discussed here where the key item to any well planned qualification schedule will be based on a thorough knowledge of the components failure modes. For programs that want to include more than one vendor per component, increased confidence of the reliability for longer duration mission and have the funding to extend the program a prescreening qualification should also be considered to insure higher reliability. In cases where the application of a particular component is challenging or vastly different from past implementations, prescreening could also be justified as a feasibility study but not for quantitative results. In most cases, budgets are tight and schedules are short and for these cases a quality-like test is conducted as a prescreening.

Once the performance requirements are supplied, the critical parameters for each component in the system can be established. Some parameters are less sensitive to environmental conditions than others. Therefore, once the critical parameters are established per component, then the deviation of those parameters will need to be addressed. For example, how much can you allow your sensor output wavelength to shift as a result of thermal changes during the mission and still provide the information necessary? Then the environmental requirements are established that allow you to compare what you have chosen as a reasonable tolerance for your critical parameters against environmental induced changes. The major environmental issues are: contamination or non metallic materials issues associated with vacuum exposure and operation, launch vibration, thermal changes as a result of orbit parameters, and radiation exposure. Also from knowledge of the failure modes or physics of failure on each of the components themselves some critical tests can be formulated to bring out a majority of the failure modes. Incorporating, the environmental testing necessary with innovative test methods that bring out the known failure modes, a qualification or characterization plan for each commercial component can be formulated. Will this mitigate all risk against failure? No, but it's a reasonable start at providing knowledge based assessments and providing the most reliable system possible given the situation of COTS usage. Even in cases of components that are part of the military qualification process, failures still occur. So completely eliminating the possibility of failures is unlikely but the probability can be greatly reduced.

For formulating a qualification plan the following approach, as illustrated in flow chart form in Figure 2, is used. 


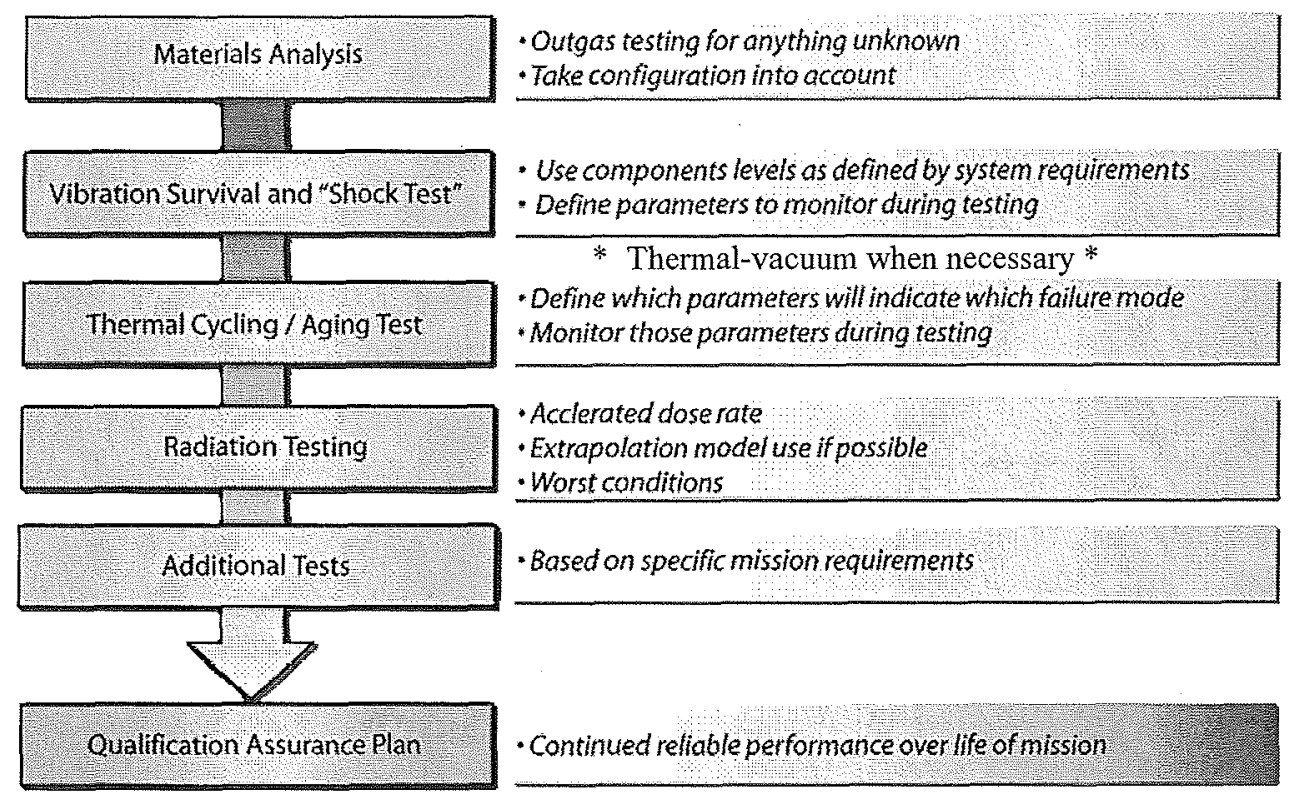

Figure 2: COTS Space Flight Qualification Plan Approach [1]

Since there are typically no space-qualified components for systems available, an approach to parts qualification of commercial-off-the-shelf for space environments is required. To insure the greatest risk mitigation, the parts selected for the instrument should be qualified by lot or batch. A "lot" is defined as a group or batch of parts that are manufactured in a short period of time with respect to each other and with the same materials. The final flight implementation is manufactured with parts from this qualified lot. A small sample from the lot is put through full qualification testing based on the construction of the component found through materials and construction analysis. The qualification method usually consists of; construction analysis and screening of any materials that are found to be noncompliant, vibration testing, thermal and/or thermal vacuum testing, and radiation testing. This is the common COTS approach used at NASA as prescribed by the NASA Parts and Packaging Program. [2-4] Figure 2 illustrates the order of testing to be performed during a COTS qualification, the details of which are described in references $2 \& 3$.

\section{PREQUALIFICATION STUDIES}

\subsection{The Lunar Reconnaissance Orbiter Applications}

Some space flight missions break new ground where technology is concerned because of the non negotiable space craft requirements. The Lunar Reconnaissance Orbiter (LRO) is an example of this for the fiber optics aboard used as part of the receiver optics for laser ranging applications. A receiver box will be placed at the end of the High Gain Antenna that will be deployed once the space craft reaches orbit. The receiver telescope will be pointed at the earth for capturing the Laser Ranging data such that a distance determination from the earth can be made. The light will then be guided back to the Lunar Orbiter Laser Altimeter (LOLA) instrument on the other side of the space craft. The light will have to be guided down the boom and around the space craft to a LOLA detector. LOLA will be pointed at the moon. Because it will be necessary to steer the High Gain Antenna towards its target, the boom arm includes gimbals that enable full $\mathrm{x}$ and $y$ motion control. Figure 3 shows an artists rendition of the LRO space craft with arrows pointed at the Laser Ranging receiver telescope and the LOLA instrument. The information gathered from both the Laser Ranging activity and the LOLA will enable scientists to enhance the gravity model and increase the resolution of measurements. 


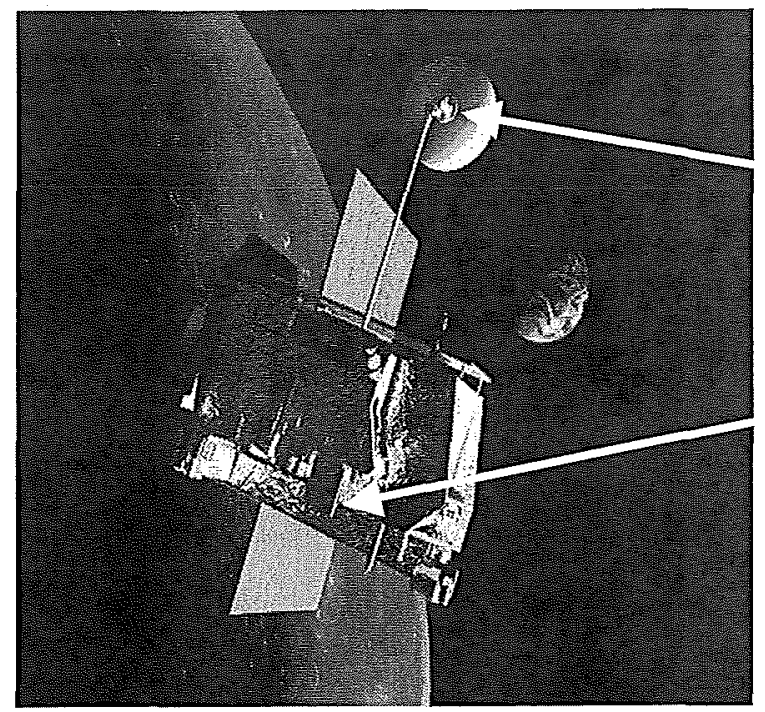

\section{Laser Ranging Receiver Telescope}

\section{LOLA Instrument}

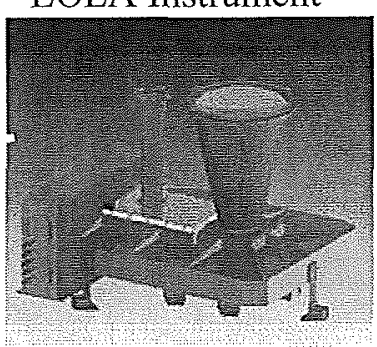

Figure 3: Artists rendition of the Lunar Reconnaissance Orbiter and position of the Laser Ranging Telescope and the LOLA instrument. [5]

The receiver box includes a seven fiber array/bundle that will transmit the signal received to the instrument in which it will be processed. The seven fiber array bundle will be constructed of Polymicro Technologies optical fiber inside of the W.L. Gore FLEX-LITETM cable. Around the bundle will be PFA over a metal braid which is typical for the space flight wire harnessing used inside space flight gimbal cable wraps. The array/bundle will basically guide the light entering the telescope from the earth into the LOLA instrument.

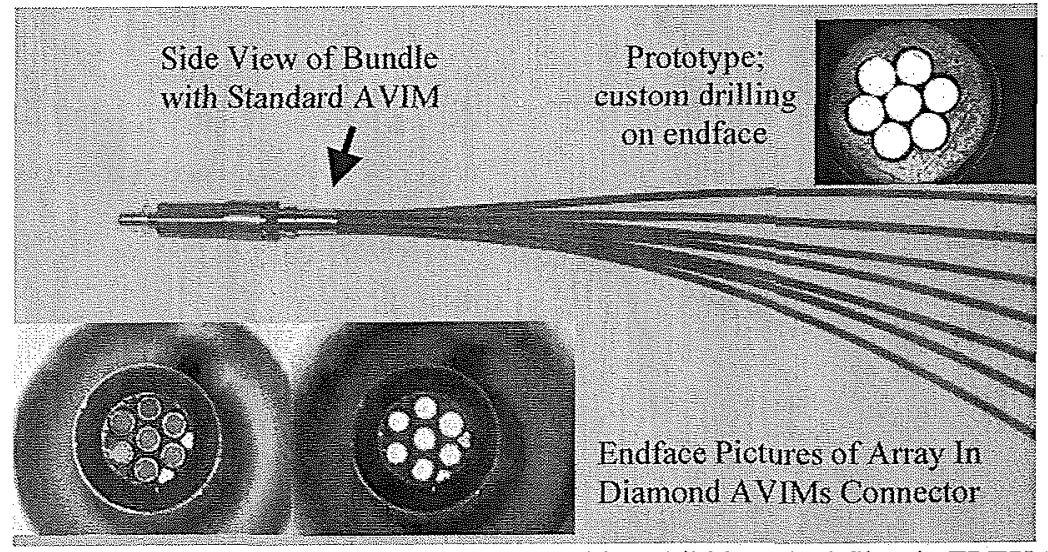

Figure 4: Early prototype of 7 optical fiber array with $300 / 330$ optical fiber in FLEX-LITE ${ }^{\text {TM }}$

This requirement means that optical fiber will be wrapped around several gimbals and in constant motion for the duration of the mission. The temperatures are expected to cycle but the worst case for fiber during motion will be at cold temperatures. Fiber will be more brittle and experience higher losses at cold temperatures. This aspect of the design represents a high risk item since no data exists that assures that losses will not be excessive and that the fiber will not be cracked by the motion of the gimbals during cold thermal exposure.

2.1.1 Laser Ranging Prequalification Testing; Thermal and Mechanical Stresses

In the case of the Laser Ranging application, it is necessary to conduct a prescreening qualification test to insure the feasibility of the implementation. A prequalification test should be designed to gather as much information as possible during environmental exposure using the least means of doing so without compromising the data of greatest interest. 
This requires priorities to be weighed against the budget and schedule constraints. Tests such as this are only for the purpose of providing insight into the reliability and can not always provide quantitative results. In order to assure that the optical fiber would survive and function adequately during cold thermal exposure during gimbaled motion, an experimental setup was constructed to prescreen the fiber under these constraints.

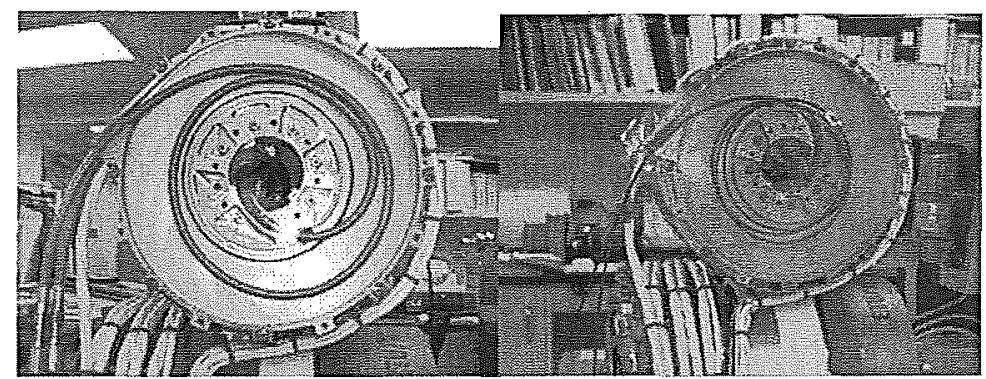

Figure 5: Inside view of routing of RF cable in gimbal, Inside view of FLEX-LITETM fiber cable in side gimbal cable wrap.

Figure 5 shows pictures of the inside of the cable wraps used in the gimbals that have been used in past space flight missions for testing purposes such as the Tropical Rainfall Measuring Mission (TRMM) but without fiber optic cable in the cable wraps. The first picture shows a cable wrap with an RF coaxial cable and the second picture shows the same gimbal with the RF cable replaced with a single strand of FLEX-LITE ${ }^{\mathrm{MM}}$ cable made by W.L. Gore containing Polymicro Technologies FIA300330500 optical fiber.

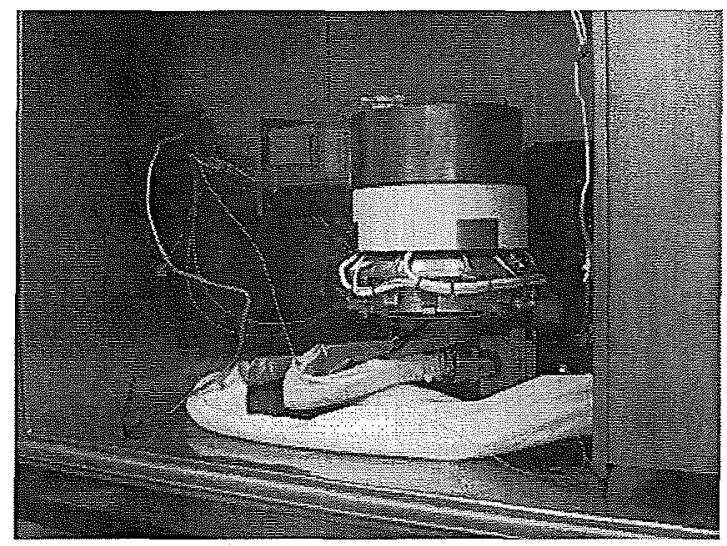

Figure 6: Picture of gimbal system in thermal chamber with cables routed through the feed through at the chamber wall.

The 4 meter single fiber strand was wrapped into two cable wraps that are stacked together as part of the gimbal configuration and routed outside of a thermal chamber. The cable was connected to source and detector reference cables with the Diamond AVIM connectors and monitored at $850 \mathrm{~nm}$ for relative insertion loss during gimbal motion. Three tests were conducted at $0^{\circ} \mathrm{C},-10^{\circ} \mathrm{C}$ and $-20^{\circ} \mathrm{C}$ while moving the gimbal 180 degrees in one dimension. A single cycle of motion consisted of gimbal motion from 0 to the 180 degree position and back and the duration of one cycle is approximately $4.75 \mathrm{~min} /$ cycle. The total number of gimbal cycles was 5500 to represent the number of cycles the gimbals would experience during the 14 month mission. Figures $7-9$ are graphs of the data collected on the last of the thermal exposed gimbal cycles during the cold flexing test. 
Gimbal Positions and Optical Insertion Loss Optical Insertion Loss

From 5590 to 5596 cycles at 0 degrees $\mathrm{C} \quad \rightarrow$ 㯺- Gimbal Positions

(Note: The fiber is tight at 0 position and loose at 180)

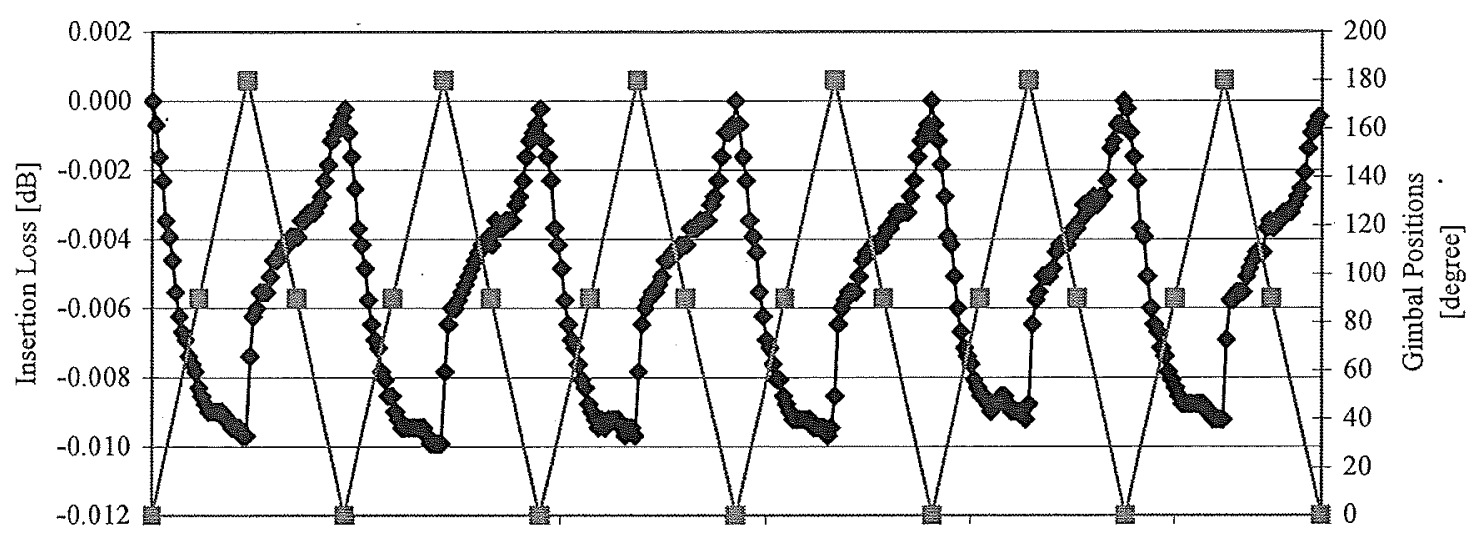

1/9/06 9:02 AM 1/9/06 9:07 AM 1/9/06 9:12 AM 1/9/06 9:17 AM 1/9/06 9:22 AM 1/9/06 9:27 AM

Date \& Time

Figure 7: Insertion loss of optical fiber cable during $0^{\circ} \mathrm{C}$ exposure during the final gimbal motion cycles. Relative insertion loss in $\mathrm{dB}$ on the left and gimbal position in degrees on the right axis.

Gimbal Positions and Optical Insertion Loss@-10C —-Optical Insertion Loss

with 5580 to 5586 cycles

- -

(Note: The fiber is tight at 0 degrees position and loose at 180 degrees)

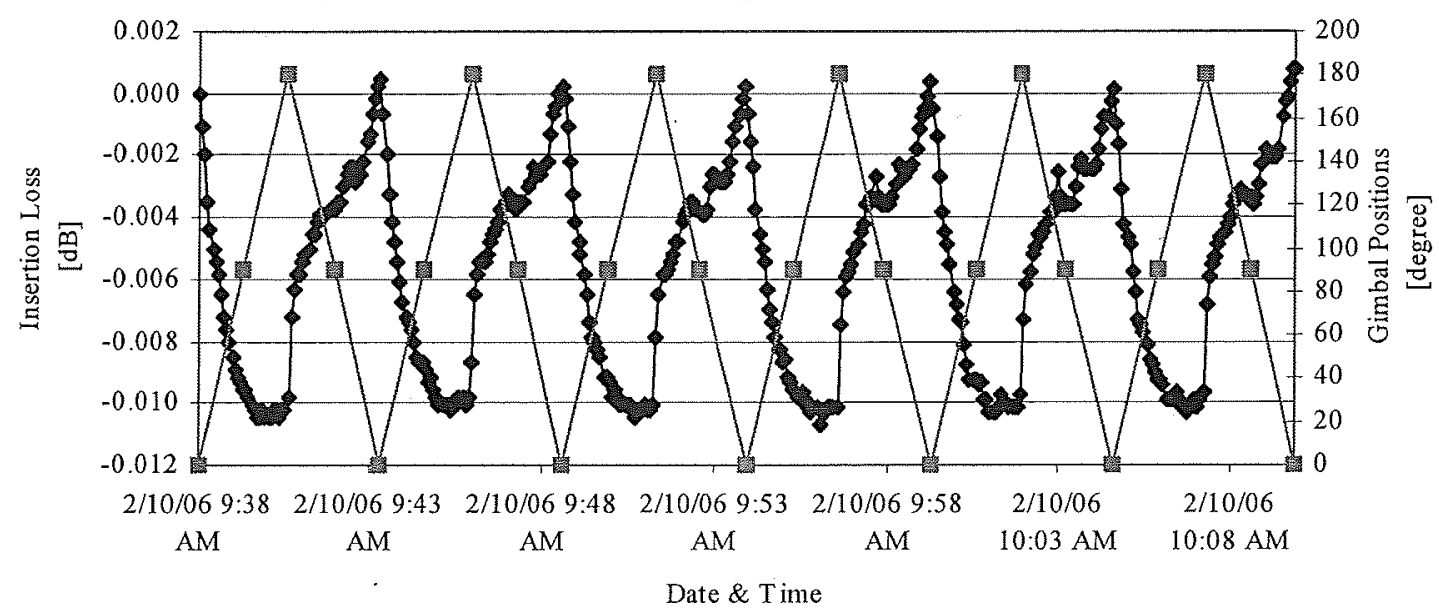

Figure 8: Optical insertion loss for the fiber cable during the final gimbal motion cycles at $-10^{\circ} \mathrm{C}$. Relative insertion loss in $\mathrm{dB}$ on the left and gimbal position in degrees on the right axis. 


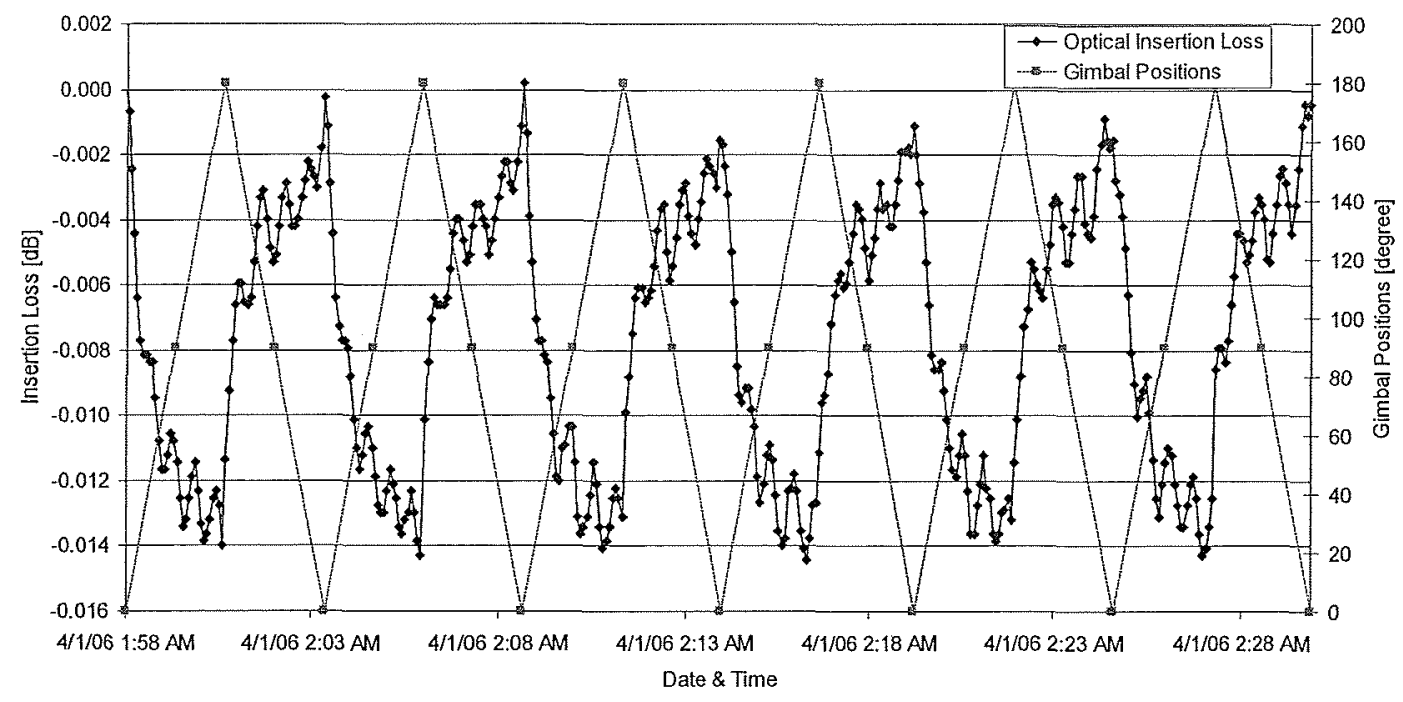

Figure 9: Optical insertion loss for the fiber cable during gimbal motion cycles at $-20^{\circ} \mathrm{C}$. Relative insertion loss in $\mathrm{dB}$ on the left and gimbal position in degrees on the right axis.

All the experiments were conducted successfully without any significant degradation of the fiber performance. The monitored insertion loss was $\sim .010 \mathrm{~dB}$ for the $0{ }^{\circ} \mathrm{C}$ test, $\sim 0.11 \mathrm{~dB}$ or less for the $-10^{\circ} \mathrm{C}$ test, and $\sim 0.14 \mathrm{~dB}$ for the $20^{\circ} \mathrm{C}$ temperature in-situ test. The test confirmed that it would be possible to wrap space flight cable in the gimbals and operate the gimbals during cold temperatures without threatening the reliability of the assembly. The engineering models and flight units will be built before the end of the year and will be qualification tested using an approach typical to that of the Mercury Laser Altimeter (MLA) [6] with additional pre-qualification for the alignment of the bundles to one another and life testing to be included for the bundle during at $-20^{\circ} \mathrm{C}$.

\subsubsection{Laser Ranging and Lunar Orbiter Laser Altimeter: Radiation Characterization Testing}

For both the Laser Ranging and LOLA application, step index undoped multimode fiber will be used. During MLA testing it was determined that in spite of the core size differences, the 200 and 300 micron core Polymicro Technologies optical fiber did not deviate in radiation performance at $-20 \mathrm{C}$. Although testing at low temperatures and shorter wavelengths does provide a more conservative estimate of the radiation induced losses, over-estimation of those losses isn't always appropriate for photon counting type applications such as LR and LOLA. Over-estimation in this case, will not provide a feasible value for the end of life losses and therefore show the necessity for additional shielding to maintain the performance requirements. Extra shielding means extra weight, which for flight programs converts directly too greater costs. The data collected during MLA did not allow for anything besides a very conservative estimate of the losses expected for especially the LR mission. Portions of the assembly will be positioned extra-vehicular and will have minimal amount of shielding during the mission. Using the MLA data will provide a bleak performance picture for the end of life predictions. Another data set was required due to this inability to predict anything besides losses during prolonged exposure to very cold temperatures. Therefore, the new flight cable for LOLA was put into a two dose rate configuration. Two samples of 10 meters long were exposed to $18.6 \mathrm{rads} / \mathrm{min}$ and $150 \mathrm{rads} / \mathrm{min}$ for the purpose of extrapolating to lower dose rates. The radiation testing was conducted at NASA GSFC Radiation Effects facility in Greenbelt Maryland. The test utilized both the high dose and low dose rate Cobalt 60 sources simultaneously. The goal was to test at two different dose rates and use the Friebele [7] Model for extrapolation to lower dose rate and total dose environments. One 10 meter sample of the Flexlite FON1173 with FIA200220500 acrylate coated fiber was placed directly in front of the input to the high dose rate source surrounded by the collimator extending from the high dose rate source. The high dose rate cable was attached to the front door of a thermal chamber that also contained devices under test. The low dose rate test was conducted in a lead box and positioned immediately in front of the lower dose rate source. The fiber in both cases was coiled such that all fiber would be exposed to the same total dose at the same dose rate. 

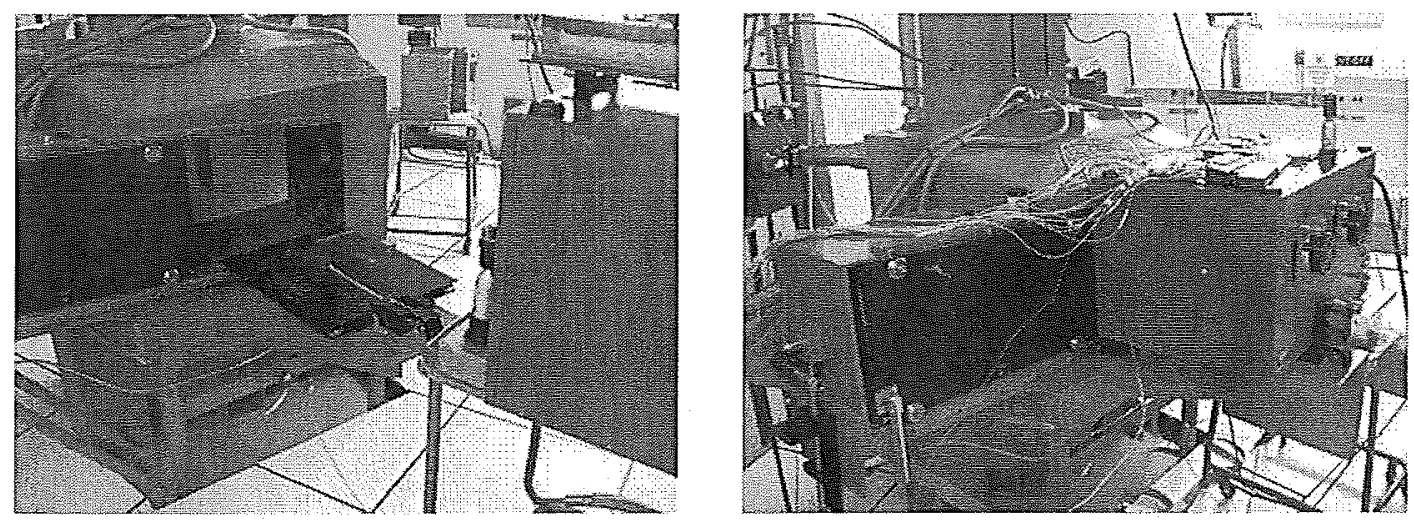

Figure 10 a) \& b): High dose rate radiation source away from the test sample and with test sample in place against input to collimator.

The low dose rate sample was positioned directly at the opening of the lower dose rate source as in Figure 11a. The fiber spool is inside the box with a dose rate sensor.
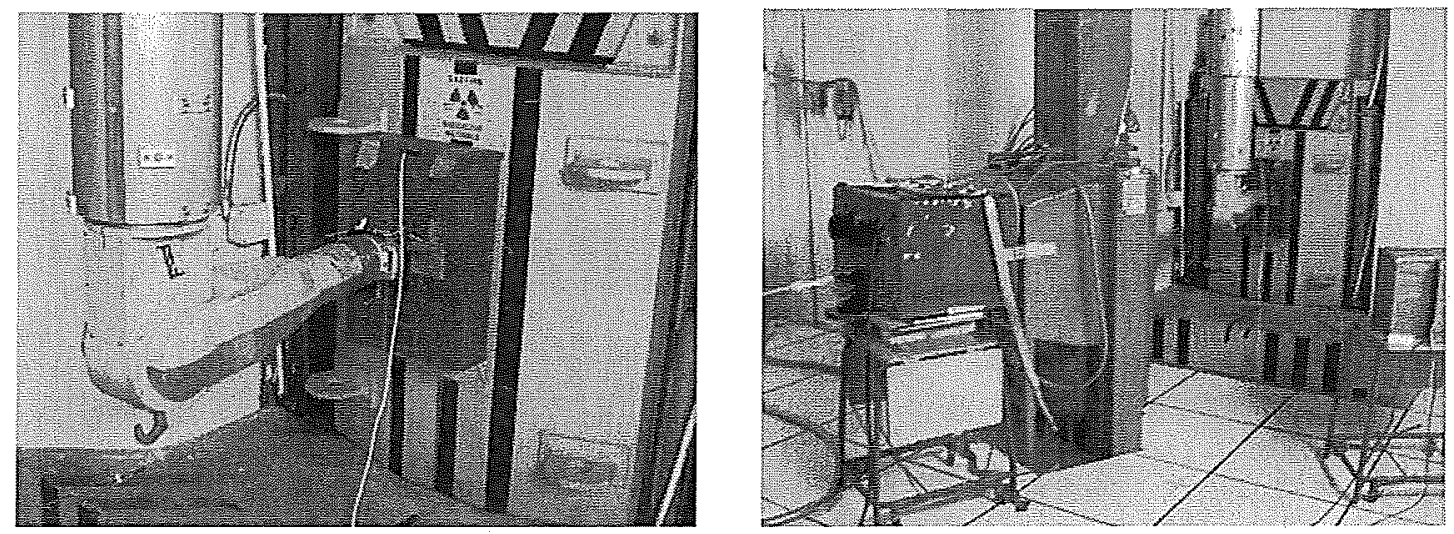

Figure 11 a) \& b) Low dose testing set up with low dose rate source door closed, and full view of both low and high dose rate experimental configurations.

One complication of the test configuration was that the high dose rate spool, attached to the front of the thermal chamber positioned to take data for another flight project, was actually not at room temperature. The data showed a thermal response during exposure to the radiation source. The spool exposed to the high dose rate source was measured at $10^{\circ} \mathrm{C}$. The experimental set up was left in place after the thermal chamber test was turned off (temperature returned to $25^{\circ} \mathrm{C}$ ) such that a reading at room temperature could be gained for the radiation sensitivity of the high dose rate sample. Since saturation behavior was expected for the high dose rate sample as was seen with the low dose rate sample, a estimation as to where the saturation point should have been, can be deduced from the available data shown in Figure 12. Where the low dose rate sample reached a saturation of less than $0.02 \mathrm{~dB} / \mathrm{m}$, for up to the total dose of $425 \mathrm{Krads}$, it is concluded that the high dose rate sample would have reached $\sim 0.065 \mathrm{~dB} / \mathrm{m}$ up to the total dose of $3.5 \mathrm{rads} / \mathrm{min}$. Although we are calling the nearly constant value of radiation induced darkening seen on the low dose rate sample "saturation" which would mean the darkening and the annealing material properties balance out to achieve a constant value, there is a slight linear increase in the low dose rate data that no doubt would have been seen in the high dose rate data had the sample been kept at room temperature as intended. Using the data results shown in Figure 12, a model to describe the radiation response over temperature, dose rate and total dose is proposed. 


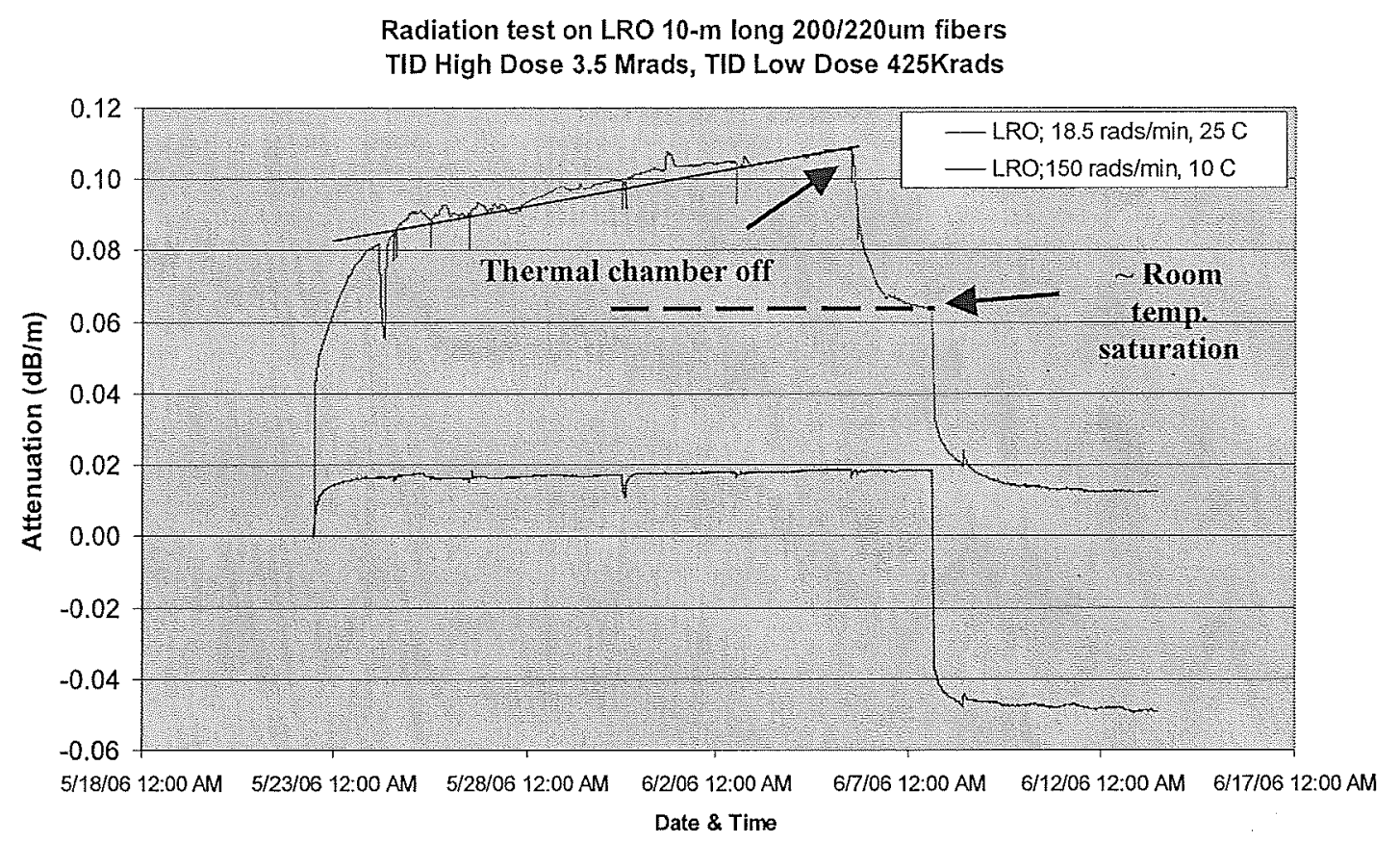

Figure 12: Low and high dose rate radiation induced darkening of the LOLA Flexlite optical cable with Polymicro Technologies FIA200/220

Based on the data used in Figure 12 and using the Friebele model [7] as a starting point, a model is proposed. The Friebele model takes the form; Radiation Induced Attenuation as a function of total dose $=$ Constant $*$ Dose rate raised to the power $1-f\left(\Phi^{1-f}\right) *$ Total Dose raised to the power $f\left(D^{f}\right)$. Therefore, the equation for low dose rate environments less than $18 \mathrm{rads} / \mathrm{min}$ would be

$$
\mathrm{A}(\mathrm{D})=4.21 * 10^{-3} \Phi^{0.904} \mathrm{D}^{0.096} \mathrm{~dB} / \mathrm{m}
$$

Lowering the temperature will increase the factor $f$. Using the data collected here, which is limited to only two data sets at temperature, a decrease in temperature of 14.4 degrees $C$, resulted in an increase in the f factor of 0.062 (from 0.096 at $24^{\circ} \mathrm{C}$ to 0.158 at $9.6^{\circ} \mathrm{C}$ ) for the low dose rate condition. If we assume a linear relationship between $\mathrm{f}$ and temperature (lower than $25^{\circ} \mathrm{C}$ ) we could estimate the conversion for increase of $f$ with temperature decrease to be $0.0043 /{ }^{\circ} \mathrm{C}$. So equation (1) for a temperature of $-70^{\circ} \mathrm{C}$ would take the form

$$
\mathrm{A}(\mathrm{D})=4.21 * 10^{-3} \Phi^{0.500} \mathrm{D}^{0.500} \mathrm{~dB} / \mathrm{m}
$$

and for $-30^{\circ} \mathrm{C}$ will take the form

$$
\mathrm{A}(\mathrm{D})=4.21 * 10^{-3} \Phi^{0.672} \mathrm{D}^{0.328} \mathrm{~dB} / \mathrm{m}
$$

The expression for calculating fhere, for any temperature $\mathrm{T}$, less than $24^{\circ} \mathrm{C}$, is

$$
f(T)=-0.0043 T+.1993
$$

This means that the radiation induced losses, using a worst case radiation environmental constraint, for $\mathrm{LOLA}$, at $-30^{\circ} \mathrm{C}$, $10 \mathrm{Krads}$, and $0.016 \mathrm{rads} / \mathrm{min}$, will not be larger than $.0054 \mathrm{~dB} / \mathrm{m}$ and since LOLA assemblies will be 0.5 meters or less this loss will be negligible in comparison to the thermal induced losses alone. For the worst case condition on the Laser Ranging cable bundle approximately 0.5 meters may experience up to $782 \mathrm{Krads}(1.28 \mathrm{rads} / \mathrm{min}$ for a 14 month mission) without additional shielding during prolonged exposure to $-70^{\circ} \mathrm{C}$ which would result in a loss of $2.1 \mathrm{~dB}$ for the end-oflife loss calculation $(4.21 \mathrm{~dB} / \mathrm{m})$. With a very slim loss budget, laser ranging will have to provide additional shielding to the exposed portions of the assembly in order to reduce the worst case end-of-life loss numbers. The temperature is not expected to stay at $-70^{\circ} \mathrm{C}$ the entire time so this estimate is extremely conservative in attempting to estimate what the 
expected losses will be. In order to really know, an estimation given a thermal cycling environment is most likely a more realistic approach that will provide a more feasible answer. When the thermal analysis for the extra-vehicular is completed those values will be used to estimate the actual losses expected using the combination of the thermal and dose rate/total dose models shown above.

\subsection{Cable Candidate Studies for Future ISS and Space Flight Missions}

The cable that was studied during the failure analysis conducted during 2000 for the International Space Station (ISS) is no longer produced by the vendor that provided the optical fiber cable used on ISS in the past.[8] There is a need to determine which optical fiber cable candidate can withstand the harsh environmental requirements of the ISS. One of the most difficult requirements is of course the $-120^{\circ} \mathrm{C}$ thermal requirement during operation. There are no space flight qualified cables that can perform well at $-120^{\circ} \mathrm{C}$. Therefore, we have been conducting thermal testing at $-120^{\circ} \mathrm{C}$. In addition to the thermal in-situ performance testing at very low temperatures, we have also been conducting thermal shrinkage evaluations of cable candidates to determine the appropriate parameters for thermal preconditioning. Thermal preconditioning is performed on all flight cables prior to termination to alleviate any permanent shrinkage that would be thermally induced over the life of the mission. [9]. In the past, many thermal studies were conducted to determine the best candidate for permanent and dynamic shrinkage and those reports are located on the NASA GSFC photonics group website.[9-10] Data from both the testing at $-120^{\circ} \mathrm{C}$ and the thermal preconditioning characterizations are presented here.

\subsubsection{Thermal precondition characterization}

For general purpose usage including ISS and other space flight missions, several cable candidates were tested for permanent thermal induced shrinkage of the fluoropolymer materials. The cables included the following: W.L. Gore FLEX-LITE TM part numbers FON-1012 and FON-1174 (heritage MLA cable), GSC-13-83034-001.8 mm outer diameter cable, and General Cable OC-1260. General Cable was the provider for the ISS fiber cable in the past. W.L. Gore is the provider of the space flight cable simplex FLEX-LITE ${ }^{T M}$ used on GLAS, MLA and will be used on LOLA and LR. Both FON1012 and FON1174 are of the same construction and they differ only in the type of fiber inside. Approximately 3 meters was tested of each type of cable for a pre qualification characterization test of the thermal induced permanent shrinkage. The results of thermal cycling from $-50^{\circ} \mathrm{C}$ to $+120^{\circ} \mathrm{C}$ at a ramp rate of no more than $2^{\circ} \mathrm{C} / \mathrm{min}$ and 1 hour dwells at the extremes is in Figure 13.

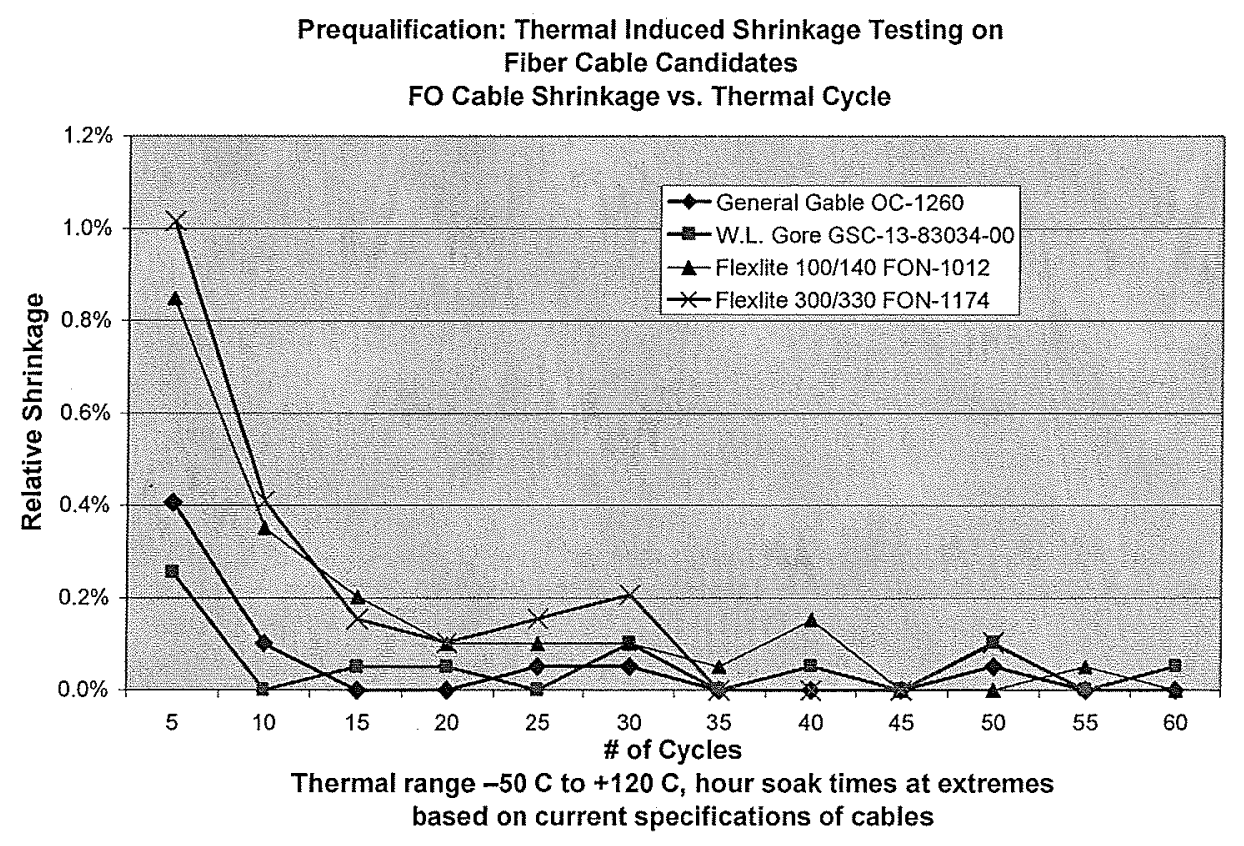

Figure 13: Thermal induced permanent shrinkage of the cable components in three candidates 
From the data presented in Figure 13, it can be concluded from a preconditioning perspective that the W.L. Gore $1.8 \mathrm{~mm}$ cable is very thermally stable. After only 10 cycles the cable is already below $0.1 \%$ for the amount of relative shrinkage. The relative shrinkage is calculated based on how much the cable components pulled back from the ends of the fiber normalized by the overall length of the cable sample. Of course this data is not statistically significant but it does provide a picture of how both the General Cable and the W.L. Gore $1.8 \mathrm{~mm}$ cable are good candidates from the thermal shrinkage perspective. The W.L.Gore FON-series cables were included as the heritage "control" to compare to other candidates.

\subsubsection{Cold Temperature Performance}

In addition to the preconditioning characterization presented above, thermal testing at the coldest temperature expected for the ISS environment was conducted at $-120^{\circ} \mathrm{C}$. For this testing, approximately 9 meters of cable was tested for several hours at $-121^{\circ} \mathrm{C}$. Although each cable may have a slightly different fiber inside it does give a initial comparison to what can be expected for the cable candidates the will eventually have $100 / 140$ graded index with $N A=0.30$. Table 1 below contains a summary of the cable candidate and its specifications.

Table 1: Cable candidate specifications for the thermal characterization testing at $-121^{\circ} \mathrm{C}$

\begin{tabular}{|l|l|l|l|}
\hline Manufacturer & Part Number & Fiber Type & Thermal Range \\
\hline W.L Gore & FON1012, FLEX-LITETM & OFS BF05202 $100 / 140 / 172$ & -55 to $+150^{\circ} \mathrm{C}$ \\
\hline General Cable & OC-1260 & Nufern (FUD-2940) $100 / 140 / 172$ & -65 to $+200^{\circ} \mathrm{C}$ \\
\hline W.L Gore & GSC-13-83034-00 $1.8 \mathrm{~mm}$ & OFS $62.5 / 125 / 245$ & -55 to $+125^{\circ} \mathrm{C}$ \\
\hline
\end{tabular}

The results of the thermal testing are presented in Figure 14.

\section{Thermally Induced Loss of \\ General Cable's OC-1260 100/140 Cable, W.L. Gore's GSC-13-83034-00 62.5/125 \& FON 1012 (100/140) Cables (1310nm @-121C)}

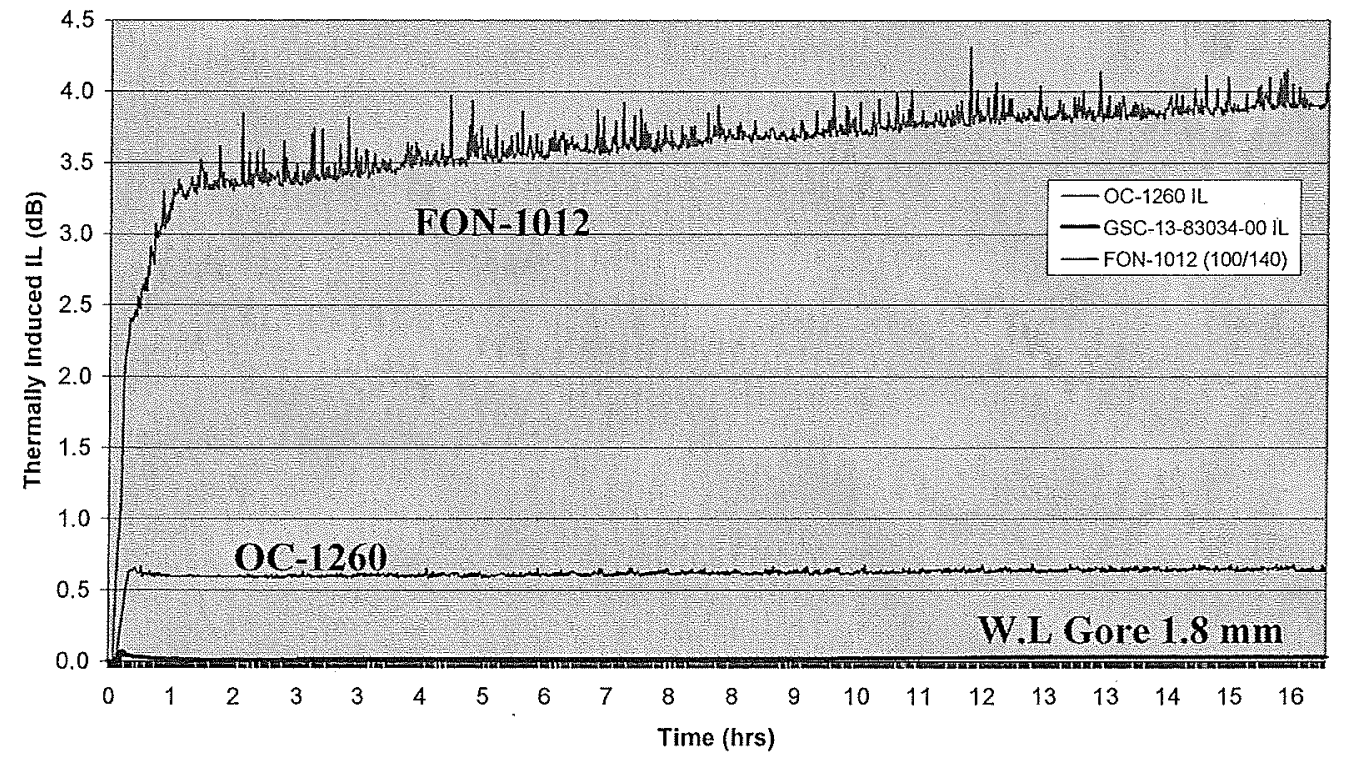

Figure 14: Thermal cold test on cable candidates at $-121^{\circ} \mathrm{C}$.

It is important to note that all of the cables in Figure 14 were taken below their rated thermal range or below their specification by over 60 degrees C. The results in Figure 14 show that the W.L. Gore $1.8 \mathrm{~mm}$ cable part number GSC-13-83034-00 performed extremely well with the General Cable OC-1260 not far behind. For this testing, the W.L. Gore $1.8 \mathrm{~mm}$ cable did not 
contain a 100/140 type optical fiber where the other two candidates did. In order to verify that the results seen here will still be valid with other types of optical fiber, additional testing is planned with the Nufern 100/140 graded index polyimide fiber. It will be noted during the next test whether the coating had a good deal to do with the thermal stability as well, since both of the other candidates had polyimide coating and the $1.8 \mathrm{~mm}$ cable had acrylate coated fiber. The FON-1012 was used as a control for comparison purposes since this is the FLEX-LITE ${ }^{\mathrm{TM}}$ cable configuration typically used in somewhat benign space flight thermal environments (not usually less than $-30^{\circ} \mathrm{C}$ ) but with a $100 / 140$ graded index optical fiber that is not used in GSFC typical LIDAR applications. More characterization and qualification testing is planned for the cable candidate that passes the next round of testing for usage on future ISS missions.

\section{CONCLUSION}

Presented here were the current activities in the Code 562 Photonics Group of the Parts, Packaging and Assembly Technologies Office at NASA Goddard Space Flight Center. The activities presented here included both communications and LIDAR applications with different requirements. It is typical to find that some components fit some space flight environments while others fit a wider range of harsh environmental parameters. This explains why FLEX-LITE ${ }^{\mathrm{TM}}$ is used in many space flight applications the involve LIDAR and why a more rugged cable is being sought for communications based applications for ISS future missions. The fiber used in each application fits the requirements set by the instrumentation. For LIDAR applications, the requirements depend on the information necessary to establish the optical interface necessary between the telescope and the detectors, where for communications requirements are already set by the existing space flight fiber optics bus called the HRDL on the International Space Station.

As part of our deliverables to the NASA Electronic Parts and Packaging Program our group will continue to publish our research and findings. Our goal is to benefit other NASA projects from the work coming from a variety of space flight programs. Our intention is to provide this information to serve and expedite all NASA space flight photonics projects. Please visit the website URL: http://misspiggy.gsfc.nasa.gov/photonics for more information regarding testing and reports on lasers, photonics, and optical fiber at NASA and NASA Goddard Space Flight Center.

\section{ACKNOWLEDGEMENT}

The authors would like to thank the following for their support of this work; Steve Brown, Yevgenity Gerashchenko, and Ken LaBel of the Radiation Effects group at NASA Goddard Space Flight Center; David C. Pfenning Code 544, Matt Showalter Mantech-Code 540, Craig Tooley, LRO Program Manager; Glenn B. Jackson LOLA Instrument Manager; and Luis A. Ramos-Izquierdo, Optics Lead on LOLA and LR; David Beverly, JSC Parts Engineer for ISS, and Joseph P. Schepis Code 544 for lending us the ETU TRMM gimbals.

We would also like to acknowledge the NASA Electronic Parts and Packaging Program (Michael Sampson and Ken $\mathrm{LaBel}$, Program Managers) for funding the dissemination of this information to the public.

Lastly, we would like to dedicate this publication to the memory of our long time friend and colleague Scott D. Kniffin from MEI and the GSFC Radiation Effects Group who assisted with this work and work of the past.

\section{REFERENCES}

1. S. Falvey's summary flowchart based on M. Ott, Components for Space Systems, Presentation for the Advanced Microelectronics and Photonics for Satellites Conference, June 23, 2004.

2. Space Flight Requirements for Fiber Optic Components; Qualification Testing and Lessons Learned, M. Ott, X. L. Jin, R. Chuska, P. Friedberg, M. Malenab, A. Matuszeski, SPIE Conference on Reliability of Optical Fiber Components, Devices, System, and Networks III, Vol. 6193.

3. Validation of Commercial Fiber Optic Components for Aerospace Environments, M. Ott, SPIE Conference on Smart Structures and Materials, Smart Sensor Technology and Measurement Systems, Vol. 5758, March 2005. http://misspiggy.gsfc.nasa.gov/photonics.

4. NASA Electronic Parts and Packaging Website: http://nepp.nasa.gov. 
5. The Lunar Reconnaissance Orbiter Website: http://lunar.gsfc.nasa.gov.

6. Optical Fiber Cable Assembly Qualification for the Mercury Laser Altimeter, M. Ott, M. Proctor, M. Dodson, S. Macmurphy, P. Friedberg, SPIE AeroSense Conference Proceedings on Enabling Photonic Technologies for Aerospace Applications V, Vol. 5104, April 2003.

7. "Extrapolating Radiation-Induced Loss Measurements in Optical Fibers from the Laboratory to Real World Environments", E. J. Friebele, M.E. Gingerich, D. L. Griscom, $4^{\text {th }}$ Biennial Department of Defense Fiber Optics and Photonics Conference, March 22-24, 1994.

8. ISS Fiber Optic Failure Investigation Root Cause Report, Internal Report to the International Space Station, Henning Leidecker and the ISS Fiber Root Cause Investigation Team, August 2000.

9. Technology Validation of Optical Fiber Cables for Space Flight Environments, M.Ott, P. Friedberg, SPIE Conference on Optical Devices for Fiber Communication II, Proceedings Vol. 421, 2000. http://misspiggy.gsfc.nasa.gov/photonics.

10. "Fiber Optic Cable Assemblies for Space Flight II: Thermal and Radiation Effects," Melanie N. Ott, Photonics For Space Environments VI, Proceedings of SPIE Vol. 3440, 1998, pages 37-46. 